The subject has also been discussed by obstetricians. Stump (Winckel's Handbuch, v. 3, p. 491) considers the responsibility of the obstetricians. Gold- wasser (Beitr. v. Geburtsch. und Gyn., v. 63 , p. 1423), declares that the obstetricians should not bear any blame when forceps have been used.

\title{
ANEURISMS OF THE RETINAL ARTERIES
}

\author{
BY \\ J. Elits Jennings, M. D., F. A. C. S. \\ ST. LOUIS, MO.
}

\begin{abstract}
Description of a case with colored plate showing the ophthalmoscopic appearances presented.
\end{abstract}

Mr. T. K., aged 21, had defective vision of the left eye and was referred to me Jan. 12, 1917, by Dr. W. F. McNary of East St. Louis. The patient first noticed this defect about two months ago and said it could not have been longer for the reason that he had played ball all summer and while at bat had to see the ball with his left eye as it came from the pitcher.

The young man is short and stockily built and appears in perfect health. He has a younger brother aged 14 who is a typical albino.

Physical Examination. The urine shows no trace of sugar or albumin. There is a slight hypertrophy of the heart but no murmur. The blood pressure is 135. The Wasserman reaction is negative. Vision of the right eye is $6 / 6$; that of the left eye 3/60. The defect of vision is central, the scotoma covering 10 degrees on all sides of the macula lutea.

Ophthalmoscopic Findings. The right fundus is normal in all respects. The left fundus presents a remarkable picture. (See Pl. IV.) The optic disc is normal. In the macular region is a large collection of dots, spots and lines of brilliant white arranged in a circle around the macula lutea. A short distance on the temporal side are more white dots and spots arranged in a semicircle. The appearances just described suggest an albuminuric retinitis or a retinitis circinata. Near the disc the retinal veins are of normal size but further on the lower ones enlarge suddenly to twice their normal size; while those above narrow almost to threads and then abruptly widen again. The extraordinary character of the picture is evident as the course of the retinal arteries are followed. The artery going directly downwards passes over a soft white, cloud-like opacity with small hemorrhages below it, and as it crosses an old hemorrhage gives off a fine branch at the very beginning of which is seen a small aneurism.

Just below this point on another branch are five aneurisms-two small and three large ones, and on the main stem one small and one large one. An artery running down and out below the macula region has a small aneurism on a branch and a large one on the main stem. The inferior nasal artery has four large and one small aneurism. Just above the three larger ones is a soft white opacity. Far up in the superior portion of the fundus on branches of the superior nasal artery are two large aneurisms. On a branch of the superior temporal artery is a large aneurism near three small hemorrhages, and above these are three soft white patches in the retina lying beneath the small arteries.

In all there are eighteen aneurisms, the larger ones having a bright central reflex. The difference in appearance between a hemorrhage and an aneurism is well shown in the upper portion of the fundus.

The patient was under observation for three months without noticeable change. On Oct. 11, 1917, nine months after the first observation, the patient called at my request for a final examination before closing this report. The changes noted were as follows: the white spots and patches in the macula region are fewer in number and the radiating figure is much 


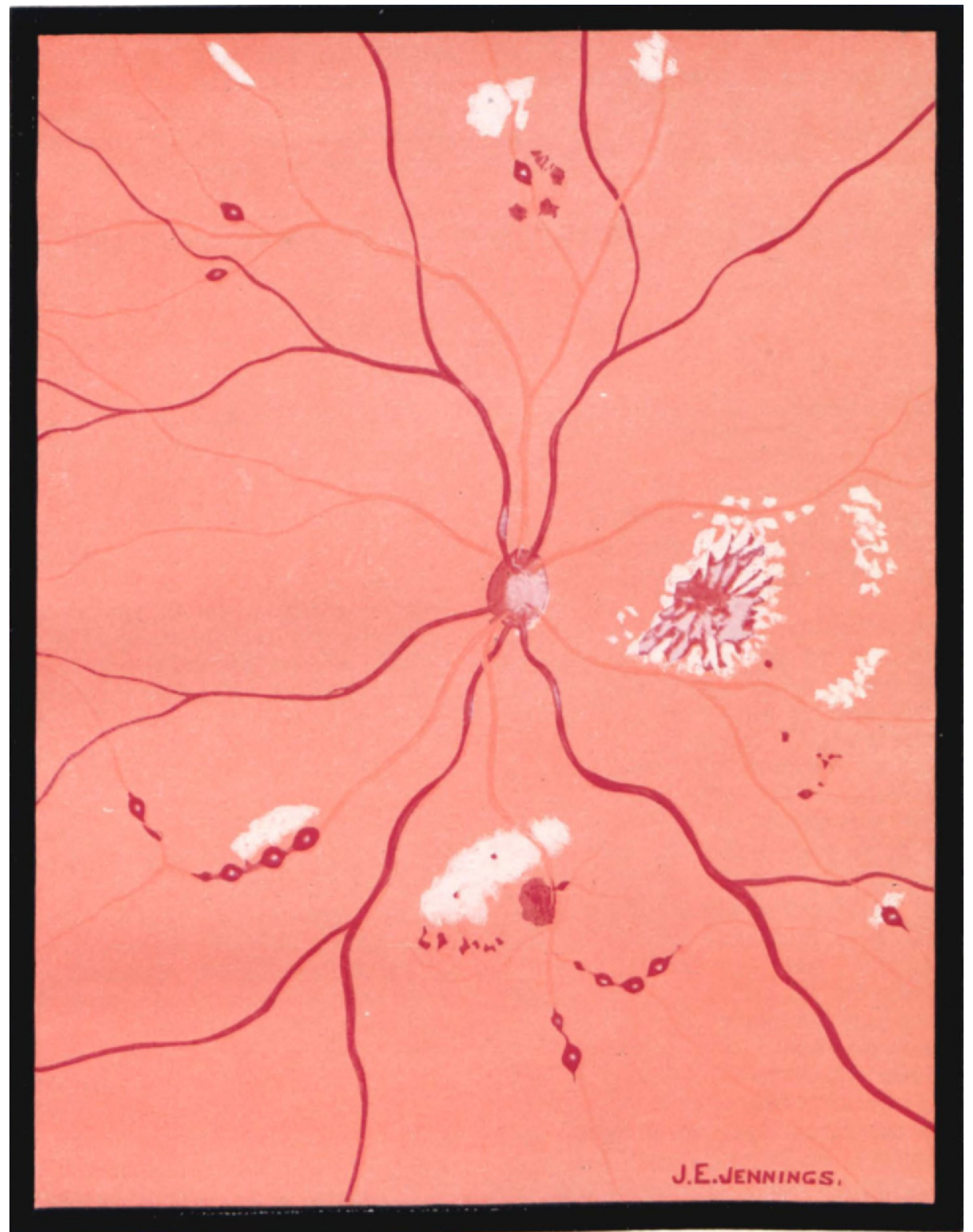

ANEURISMS OF tHE RETINAL ARTERIES JENNINGS' CASE. 
less marked. Extending out in both directions just below the disc is a long band of small white dots that I had not observed before. The first and second aneurisms on the inferior nasal artery have coalesced into a sacculated or sausage like enlargement. The small aneurism on the first branch of the artery run- ning downward is much larger than it was and several of the aneurisms below this point are concealed in a whitish exudation.

The etiology of this rare condition is obscure. Probably it is the result of local inflammation and degeneration of the walls of the retinal vessels.

\title{
PRIMARY SYPHILIS OF PALPEBRAL CONJUNCTIVA
}

BY

\author{
Edward E. Maxey, M. D. \\ BOISE, IDAHO.
}

Report of a case affecting the inferior fornix; with tabulation of the cases of chancre of the lids and conjunctiva reported since January, 1900, with bibliography.

A casual examination of the literature convinced me that chancre of the conjunctiva was by no means a common condition, which prompts me to report a case occurring in my practice recently, and also to give you the benefit of my survey of the literature on this subject. For obvious reasons I have not attempted to search the literature farther back than January 1, 1900.

According to Ginzburg (28) the first reported case of primary lid chancre was reported by Ricord in 1850 . Many cases have been reported since then, but just how many I am unable to determine from the literature and help at my disposal. I know of no one who has attempted to make a complete compilation of all recorded cases of eye chancre, and those giving any extensive compilation vary greatly in their estimates of the number of cases reported.

In 1904, Terrien (80) made the statement that there were at that time scarcely more than twenty cases of conjunctival chancre known. Ginzburg (28), in 1910, was able to find in the Russian literature alone about 210 cases of primary lid chancre and 27 cases (28 including case reported by him at that time) of primary syphilis of the conjunctiva. In 1915, Finlay (19), in the literature at his disposal, was able to find about 100 cases of palpebral syphilis, and from different writers the total summing up of cases, he said, seemed to be near 500. Wolfrum and Stimmel (77), in
1910, report two cases of primary syphilitic affection of the conjunctiva and make the claim that their cases make a total of 71 cases of conjunctival chancre reported.

Spratt (71), in 1913, reports a most interesting and rare case of lues of the bulbar conjunctiva. In his review of the literature he was able to find only 21 cases of lues primarily affecting the bulbar conjunctiva, his own case making 22 . Of these only three were located at the limbus. I have been able to add 14 additional cases of bulbar chancre to those cited by Spratt.

Quoting from Rouvillois (63), Spratt says the relative frequency in which the structures of the eye may be primarily involved are: (1) the lid margin, (2) skin of lid, (3) palpebral conjunctiva, (4) culdesac, (5) bulbar conjunctiva (scleral portion, inner angle and caruncle), (6) limbus and cornea. If we keep in mind the fact that from six to seven per cent (Spratt) to nine or ten per cent (Fournier, cited by Spratt) of all primary lesions are extragenital, and, further, that in frequency of attack the eye ranks after the lip and finger (Alter) (1), or after the lip, breast, mouth, finger, hands and tonsils (Muncheimer, cited by Alter), with chancre of the culdesac or fornix ranking fourth in frequency of the eye chancres, we may arrive at a fairly accurate idea of the relative infrequency of primary lues of the fornix. 